\title{
Automated rain rate estimates using the Ka-band ARM zenith radar (KAZR)
}

\author{
A. Chandra ${ }^{1}$, C. Zhang ${ }^{1}$, P. Kollias ${ }^{2}$, S. Matrosov ${ }^{3}$, and W. Szyrmer ${ }^{2}$ \\ ${ }^{1}$ Rosenstiel School of Marine and Atmospheric Sciences, University of Miami, Miami, Florida, USA \\ ${ }^{2}$ Department of Atmospheric and Oceanic Sciences, McGill University, Montreal, Canada \\ ${ }^{3}$ Cooperative Institute for Research in Environmental Sciences, University of Colorado and NOAA/Earth System Research \\ Laboratory, Boulder, Colorado, USA
}

Correspondence to: A. Chandra (achandra@rsmas.miami.edu)

Received: 14 January 2014 - Published in Atmos. Meas. Tech. Discuss.: 25 February 2014

Revised: 1 September 2015 - Accepted: 1 September 2015 - Published: 14 September 2015

\begin{abstract}
The use of millimeter wavelength radars for probing precipitation has recently gained interest. However, estimation of precipitation variables is not straightforward due to strong signal attenuation, radar receiver saturation, antenna wet radome effects and natural microphysical variability. Here, an automated algorithm is developed for routinely retrieving rain rates from the profiling Ka-band (35-GHz) ARM (Atmospheric Radiation Measurement) zenith radars (KAZR). A 1-dimensional, simple, steady state microphysical model is used to estimate impacts of microphysical processes and attenuation on the profiles of radar observables at $35-\mathrm{GHz}$ and thus provide criteria for identifying situations when attenuation or microphysical processes dominate KAZR observations. KAZR observations are also screened for signal saturation and wet radome effects. The algorithm is implemented in two steps: high rain rates are retrieved by using the amount of attenuation in rain layers, while low rain rates are retrieved from the reflectivity-rain rate $\left(Z_{e}-R\right)$ relation. Observations collected by the KAZR, rain gauge, disdrometer and scanning precipitating radars during the DYNAMO/AMIE field campaign at the Gan Island of the tropical Indian Ocean are used to validate the proposed approach. The differences in the rain accumulation from the proposed algorithm are quantified. The results indicate that the proposed algorithm has a potential for deriving continuous rain rate statistics in the tropics.
\end{abstract}

\section{Introduction}

Precipitation is a key variable in the Earth's water cycle. It is fundamental to atmospheric processes on a wide range of scales, and it is one of the most important components of weather and climate prediction models. Observations of precipitation associated with all cloud types are needed to improve our understanding of the life cycle of the atmospheric convection, and their interaction with the circulation, and their roles in global weather and climate (Zhang, 2013). Structures of cloud and precipitation systems span over a large spectrum of scales. Holistic, continuous ground observations across the scales of time, space and intensity are difficult to collect even at heavily instrumented sites (Mather and Voyles, 2013). More often than otherwise, only parts of the systems are observed.

This is particularly true in the tropics where operational precipitation radar networks are extremely rare. Tropical Rainfall Measurements Mission (TRMM, Kummerow et al., 1998) has collected observations of tropical rainfall that allow climatology of tropical precipitation for more than 10 years (Wang et al., 2013). NASA's CloudSat Cloud Profiling Radar (Lebsock and L'Ecuyer, 2011) provided unprecedented details of tropical cloud and precipitation. Multisatellite based precipitation products yield information at finer temporal scales (Huffman et al., 2007). However, characterizing precipitation from cloud systems with short life times (within an hour) demands observations at much finer temporal resolutions, which is a challenge for remote sensing measurement from space. Conventional methods of retrieving precipitation from low frequency (S-, C- or X-band) 
ground-based radars use different regime dependent relations between rain rate and radar measurables.

There are various approaches of deriving precipitation from different instruments depending on the measurable quantity. Profilers (UHF, ultra-high frequency or VHF, very high frequency or combination of both) are used to derive raindrop size distributions along with vertical air motions information (e.g., Wakasugi et al., 1986; Rajopadhyaya et al., 1998) as they could detect precipitation echoes simultaneously with echoes from the ambient atmosphere. For nonpolarimetric precipitation radars operating at lower frequencies (e.g., at C- and S-band), rain rates are usually derived from the observed reflectivity values using empirical reflectivity $\left(Z_{e}\right)$-rain rate $(R)$ relations, in which $Z_{e}$ and $R$ are functions of drop size distributions (DSDs) (e.g., Marshall and Palmer, $1948)$. The polarization capability $\left(Z_{\mathrm{DR}}\right.$ : differential reflectivity, $\phi_{\text {DP }}$ : differential phase) offers a possibility of estimating the DSD parameters from radar measurements of differential backscatter properties (e.g., Sachidananda and Zrnic, 1987; Ryzhkov and Zrnic, 1996), thus potentially providing more accurate estimates of rainfall rates.

Many permanent Atmospheric Radiation Measurement (ARM) Program observational sites have collected a long record of data on precipitating and non-precipitating clouds from millimeter wavelength cloud radars without accompanying precipitation radars (e.g., Kollias et al., 2007; Mather and Voyles, 2013). The millimeter wavelength cloud radars are primarily designed is observe only clouds, and their application to observe precipitation is limited due to strong attenuation by raindrops (e.g., Lhermitte, 1990) and radar receiver saturation in the lowest $1-2 \mathrm{~km}$. Nevertheless, recent studies (e.g., Aydin and Daisley, 2002; Matrosov, 2005, 2007) have demonstrated the use of millimeter wavelength cloud radars for retrieving rain rates during stratiform conditions utilizing information on signal attenuation in the rain layer.

In this study we describe an approach which extends the utility of zenith-looking Ka-band $(\sim 35 \mathrm{GHz})$ cloud radar measurements for routine estimations of rain rate. Given that Ka-band radars are deployed at many permanent and mobile locations throughout the world, such estimates would be useful in future applications especially for observational sites when retrievals from more conventional approaches that utilize lower frequency (e.g., X-, C-, or S-band) scanning radar measurements are unavailable or limited in time and/or vertical resolution (e.g., due to remoteness of scanning radar locations). The potential advantages of rainfall retrievals from zenith-looking radar measurements compared to more direct ground-based sensor estimates from gauge and/or disdrometers is in an ability to provide vertically resolved information. However, it is necessary to evaluate the robustness of the zenith looking Ka-band radar rain rate estimates with more direct results when they are available, which is the case in the present study.

\section{Data sets and instruments}

The evaluation of the Ka-band radar based approach to estimate rain rate was performed using data set obtained during the DYNAMO (Dynamics of the Madden-Julian Oscillation)/AMIE (ARM MJO Investigation Experiment) field campaign which took place in the tropical Indian Ocean and surrounding regions between 1 October 2011 and 31 March 2012 (Yoneyama et al., 2013). Several groundbased radars along with other instruments were deployed for this campaign at the Addu Atoll of the Maldives (Fig. 1). The instruments and their specifications are listed in Table 1. The radar triad consisted of two scanning precipitation radars and the vertically pointing Ka-band Atmospheric Radiation Measurement (ARM) zenith radar (KAZR) radar, which was deployed at the Gan Island airport as part of the ARM Mobile Facility (AMF).

One scanning radar had a polarimetric and a dualwavelength $\mathrm{S}$ - and Ka-band (i.e., the S-PolKa radar) capabilities and was located on Hithadhoo Island $\left(0.6304^{\circ} \mathrm{S}\right.$, $73.1029^{\circ} \mathrm{E}$ ) at a distance of $8.61 \mathrm{~km}$ from the KAZR. The other scanning radar (i.e., the Shared Mobile Atmospheric Research \& teaching Radar - the SMART-R radar) was nonpolarimetric and operated at a C-band frequency and in $10 \mathrm{~min}$ scan cycles. It was located on the same island $\left(0.6076^{\circ} \mathrm{S}, 73.0958^{\circ} \mathrm{E}\right)$, which was about $9.28 \mathrm{~km}$ from the KAZR. Vertical scans over the KAZR, were performed by both the S-PolKa (every $15 \mathrm{~min}$ ) and the SMART-R (every $10 \mathrm{~min}$ ), allowing comparisons between radar and direct estimates of rainfall from gauge and disdrometer data. For the DYNAMO period, the data from the KAZR, SMART-R and S-PolKa are merged into a single data set (Feng et al., 2014), which was used in this study.

The ARM KAZR radars provide vertical profiles of three Doppler moments (reflectivity, Doppler velocity and spectrum width). These radars are usually operated at a vertical and time resolutions of $30 \mathrm{~m}$ and $4 \mathrm{~s}$ with a maximum range of about $18 \mathrm{~km}$. During DYNAMO, two KAZR measurement modes were used: a general mode and a cirrus mode. The KAZR sensitivity for the general and cirrus modes are approximately $-25 \mathrm{dBZ}$ at $10 \mathrm{~km}$, and $-36 \mathrm{dBZ}$ at $10 \mathrm{~km}$, respectively. The KAZR systems have higher dynamic range than the millimeter wavelength cloud radars ( $\sim 85 \mathrm{~dB}$ compared to $\sim 65 \mathrm{~dB}$ ) operating in general mode, which enables the avoidance of early receiver saturation during precipitation. KAZR data used in this study were taken from the KAZR ARSCL (Active Remote Sensing of Clouds) product from the ARM data archive (www.arm.gov/kazr). This product provides cloud boundaries and best estimates of time-height fields of radar moments. In this product, the KAZR radar observations are corrected for water vapor attenuation and velocity folding and non-significant (nonhydrometeors) echoes are removed. The corrected KAZR measurements along with the observations from the micropulse lidar (MPL), ceilometer, soundings, rain gauge, and 


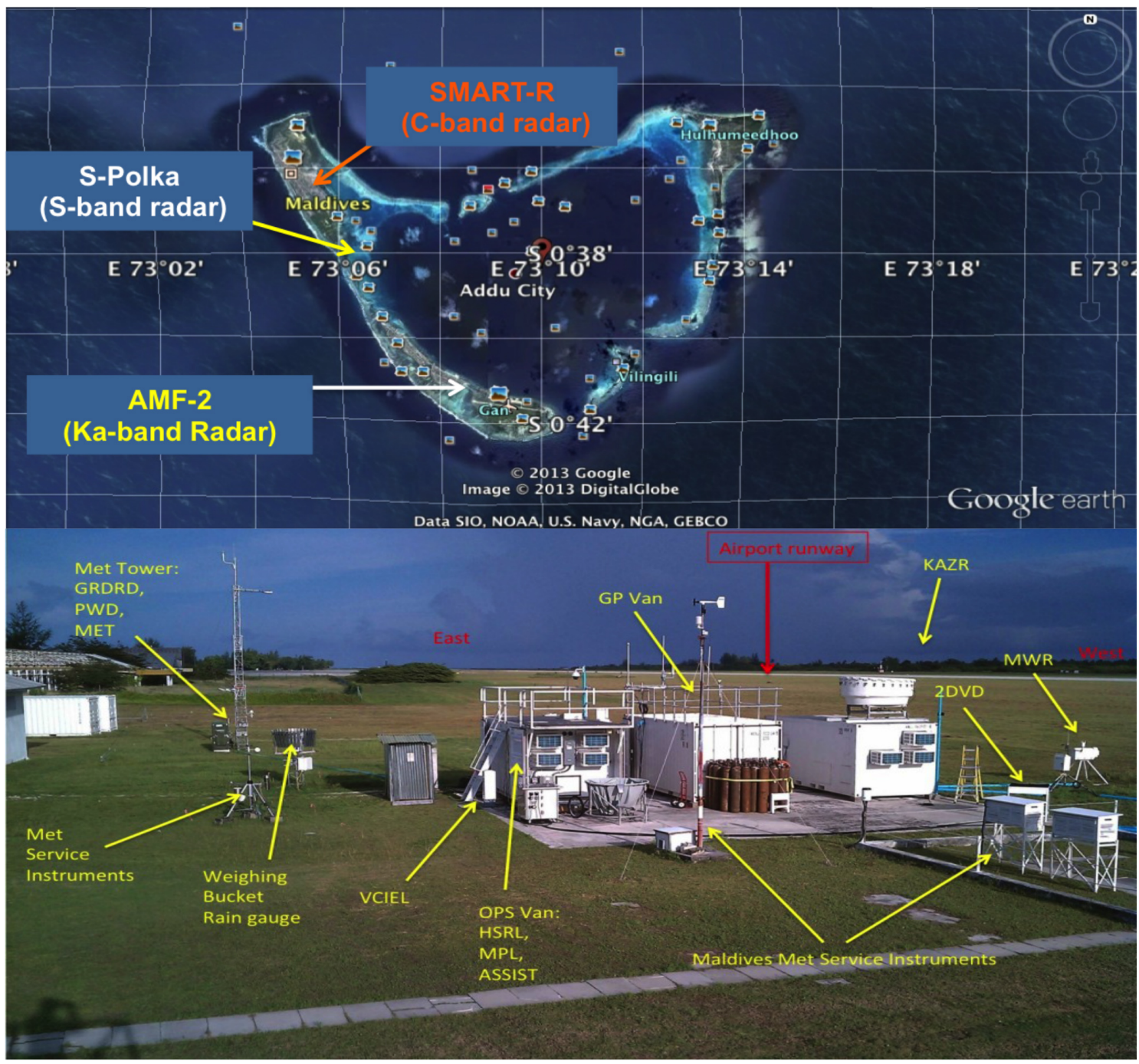

Figure 1. Top: aerial view of the radar triad on Addu Atoll (top) and AMF-2 instrument setup at Gan Island (bottom) during the DYNAMO/AMIE field campaign.

Table 1. Specifications of radars used in this study.

\begin{tabular}{|c|c|c|c|}
\hline Radar wavelength/frequency & Range, resolution & Beamwidth, sensitivity & Remarks \\
\hline KAZR $(8.66 \mathrm{~mm} / 35 \mathrm{GHz})$ & $15 \mathrm{~km}, 30 \mathrm{~m}$ & $0.3^{\circ},-45 \mathrm{dBZ}$ at $1 \mathrm{~km}$ & Vertically pointing \\
\hline \multirow{4}{*}{$\begin{array}{l}\text { S-PolKa }(10 \mathrm{~cm} \text { for S-band, } \\
0.8 \mathrm{~cm} \text { for Ka-band }) \\
\text { SMART-R }(5 \mathrm{~cm})\end{array}$} & $150 \mathrm{~km}, 150 \mathrm{~m}$ & $0.91^{\circ},-30 \mathrm{dBZ}$ at $8.5 \mathrm{~km}$ & Scanning: 8PPIs $\left(0.5-11^{\circ}\right)$ \\
\hline & & & 55 RHIs $\left(0-45^{\circ}\right) 8.62 \mathrm{~km}$ apart from KAZR \\
\hline & $150 / 300 \mathrm{~km}, 100 \mathrm{~m}$ & $1.5^{\circ},-21 \mathrm{dBZ}$ at $10 \mathrm{~km}$ & 25 PPIs $\left(0.5-33^{\circ}\right)$ \\
\hline & & & RHI over KAZR $9.28 \mathrm{~km}$ from KAZR \\
\hline
\end{tabular}

microwave radiometer (MWR) are combined to provide two data streams in the KAZR-ARSCL product: one with cloud base and cloud layer boundaries, and the other including additional best estimates of time-height fields of radar moments. Figure 2 shows an example of Doppler moments from the KAZR and S-PolKa during a stratiform rain event. The sharp gradients of reflectivity and Doppler velocity at $\sim 5 \mathrm{~km}$ indicate the presence of the melting layer. The loss of KAZR reflectivity data corresponding to the heavy rain episodes for the periods 01:00-02:00 and 04:00-05:00 UTC is due to the total extinction of KAZR signals in rain compared to $\mathrm{S}$ PolKa.

The rain measuring surface-based instruments collocated with the KAZR included an optical rain gauge (Short et 

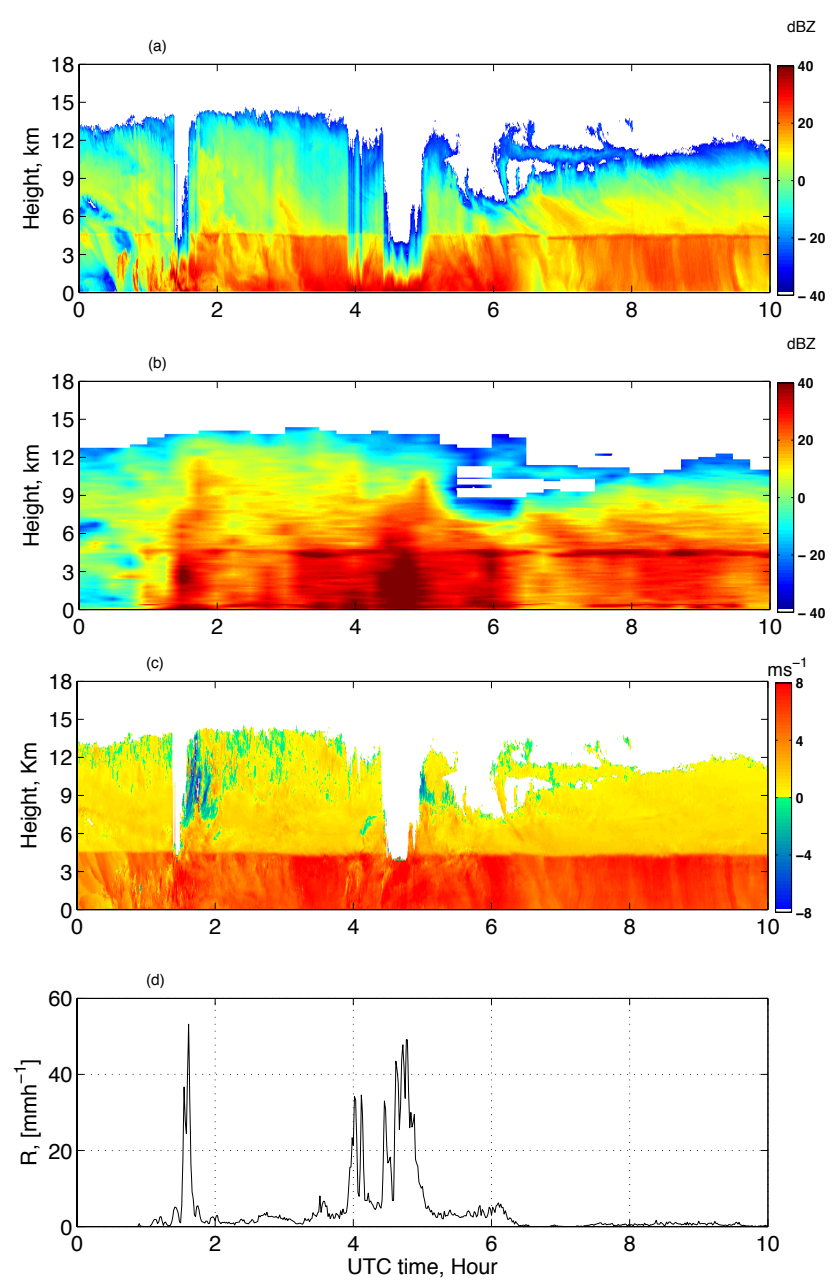

Figure 2. An example of time series of reflectivity from KAZR (a), reflectivity from S-PolKa (b), Doppler velocity from KAZR (c), and surface rain rates from an optical rain-gauge (d). Positive Doppler velocities in panel (c) represent downward velocities.

al., 1994) and a 2-dimensional video disdrometer (2-DVD). This disdrometer provided measurements of size and velocity distributions of falling hydrometeors. It is comprised of video cameras capable of observing individual hydrometeors from two viewing directions, which are perpendicular to each other. The 2-DVD disdrometer illuminates the hydrometeors from two sides, which allows the determination of size and fall velocity of particles. The rain rates are calculated from the observed drop size distributions. The details of the instrument can be found in Kruger and Krajewski (2002). The optical rain gauge provides rain rates. It has an uncertainty of $\pm 0.1 \mathrm{~mm} \mathrm{~h}^{-1}$.

\section{KAZR algorithm of rain rate retrieval}

\subsection{Retrieval algorithm}

Figure 3 shows the flow chart that explains the steps taken in retrieving the rain rate $R$ using KAZR observations. The reflectivity and Doppler velocities are averaged over $1 \mathrm{~min}$, to reduce the effect of vertical wind and wind drift effects. The presence of rain in the profile is identified if the maximum reflectivity is greater than $-10 \mathrm{dBZ}$. The rain aloft is considered to reach the ground if the average radar reflectivity and mean Doppler velocity in the layer between 200 and $400 \mathrm{~m}$ a.g.l. (above ground level) exceed $10 \mathrm{dBZ}$ and $3 \mathrm{~m} \mathrm{~s}^{-1}$, respectively. In this study a total of 3149 rain cases $(1 \mathrm{~min})$ with rain reaching the ground were identified.

The next algorithm step is to identify the portion of the $Z_{e}$ profile that saturates the KAZR receiver. KAZR saturation occurs at high rain rates where attenuation is the main contributor to the observed $Z_{e}$ profile. Thus, it is anticipated that the maximum reflectivity will be observed at the lowest usable KAZR range gate, and subsequently $Z_{e}$ will decrease with height due to signal attenuation. If the maximum $Z_{e}$ is not observed at the first gate, the maximum radar reflectivity in the lowest $1 \mathrm{~km}$ is searched. The rain layers below the first maximum in reflectivity are not taken into account to avoid the KAZR receiver saturation effects. Most of the observed saturated layers are located below $300 \mathrm{~m}$ above ground level. Out of the total 3149 rain cases identified, 51 have saturated layer tops greater than $300 \mathrm{~m}$ and were excluded from the rain retrieval.

All 1 min rain cases were classified into two main regimes: rain events with dominant attenuation effects, and the rain events with negligible attenuation effects. The automated algorithm is implemented in two stages: the (i) attenuation based technique and the (ii) $Z_{e}-R$ technique.

\subsection{1 $A-R$ based rain rate estimation}

This section explains the details of the technique to retrieve rain rates based on the amount of attenuation in the rain layer at Ka-band. Matrosov (2005) demonstrated that at $35 \mathrm{GHz}$ there is a nearly linear relation between specific attenuation (A) and $R$. The linearity of this relation and its low sensitivity to the DSD details is explained by the fact that at Ka band both $A$ and $R$ are approximately proportional to the 3.65th DSD moment (Matrosov et al., 2006). These authors used this relation to retrieve layer-average rain rates from a vertically pointing Ka-band radar and showed that relative retrieval errors generally increase for lighter rainfall when reflectivity changes due to attenuation become smaller compared to vertical changes of non-attenuated reflectivity. An important advantage of this attenuation-based method is that the retrieval of the rain rate is independent of radar calibration as it does not depend on the absolute reflectivity values. The mean layer rain rate is proportional to the reflectivity 


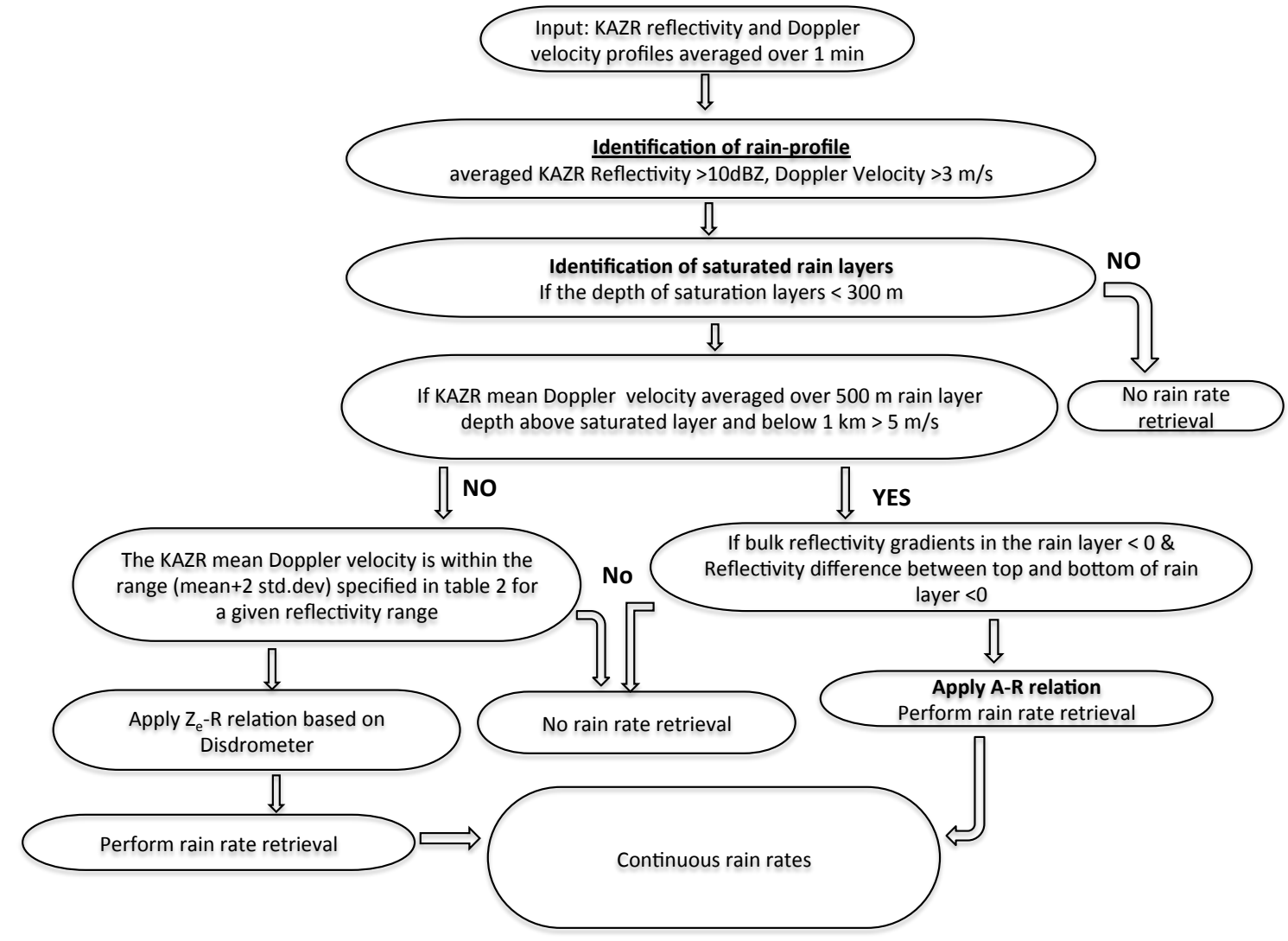

Figure 3. Flowchart of sequential steps for retrieving rain rates from the KAZR observations (reflectivity and Doppler velocity). The rain layers selected for the retrievals are below $1 \mathrm{~km}$ above the ground level for all the cases.

gradient expressed in logarithmic units:

$R\left(\mathrm{~mm} \mathrm{~h}^{-1}\right)=k(2 c)^{-1}\left(\frac{\Delta Z_{e}}{\Delta h}\right)$,

where $Z_{e}$ is reflectivity in logarithmic units, $\Delta Z_{e}$ the difference of reflectivity between the top and bottom of the layer considered, and $\Delta h$ the depth of the rain layer. The coefficient $c$ is about $0.28 \mathrm{~dB} \mathrm{~km}^{-1} \mathrm{~h} \mathrm{~mm}^{-1}$ (Matrosov, 2005). The coefficient $k$ (dimensionless) accounts for changes in the raindrop fall velocity due to changes in air density ( $\rho$ in $\mathrm{kg} \mathrm{m}^{-3}$ ), such that $k(h) \approx \rho(h)^{-0.45}$, where $h$ is the height above the ground level. Equation (1) assumes that the twoway attenuation effect of the rain layer is dominant compared to reflectivity changes within the layer due to microphysics.

The rain layer of depth of $500 \mathrm{~m}$ is chosen starting from the lowest location of the identified unsaturated radar resolution gate, which is located lower than $250 \mathrm{~m}$ for most of the cases. Thus, the top of the rain layers considered for the retrievals performed here are located below $800 \mathrm{~m}$ for most of the cases. The reflectivity difference between the top and bottom of the layer and the bulk reflectivity gradients between each gate in the rain layer are calculated. The rain layer suitable for the attenuation technique was identified when both the reflectivity difference between the top and bottom of the rain layer and reflectivity gradients in each gate are negative in order to minimize the effect of clouds. Because of practical limitations of detecting cloud bases during precipitation, it is very difficult to identify the presence of contaminating cloud layers when selecting of rain layers for attenuationbased retrievals. The average of the hourly cloud base heights for non-precipitating clouds was around $800 \mathrm{~m}$ during the project. Assuming that this cloud base height is representative also for the precipitating periods, the cloud contamination of rain layers considered here for retrievals is not likely. While applying the proposed rain rate algorithm to other locations, the depth of the rain layers has to be adjusted based on the cloud base location in that region.

For the attenuation technique to work, it is necessary that the changes in reflectivity in the rain layer due to attenuation are greater compared to changes due to microphysics (non-attenuation effects). Since attenuation affects S-band S-PolKa reflectivities negligibly, these reflectivities can be treated as unattenuated and therefore the reflectivity changes in the rain layer observed by the S-PolKa above the KAZR are mainly caused by changes in rain microphysics. The reflectivity changes due to microphysics are assessed by subtracting the S-PolKa reflectivity change from the KAZR reflectivity change. The removed outliers accounted for only 

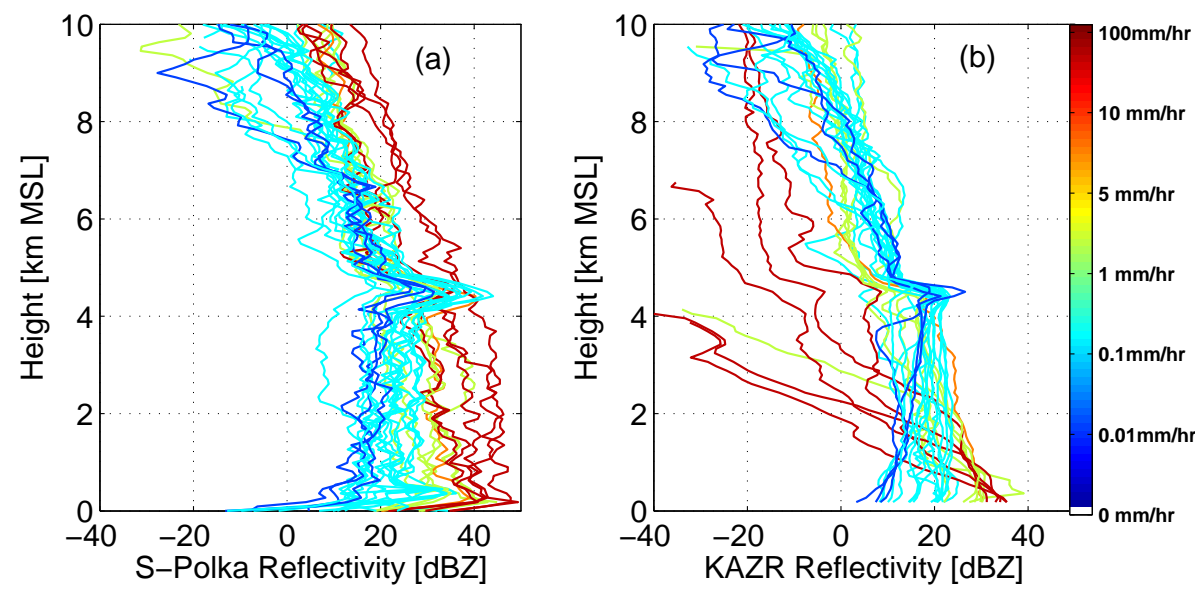

Figure 4. Illustration of rain-rate retrieval under a stratiform rain condition. (a) Reflectivity profiles of the S-PolKa for different rain rates. (b) Reflectivity profile of the KAZR for different rain-rates.
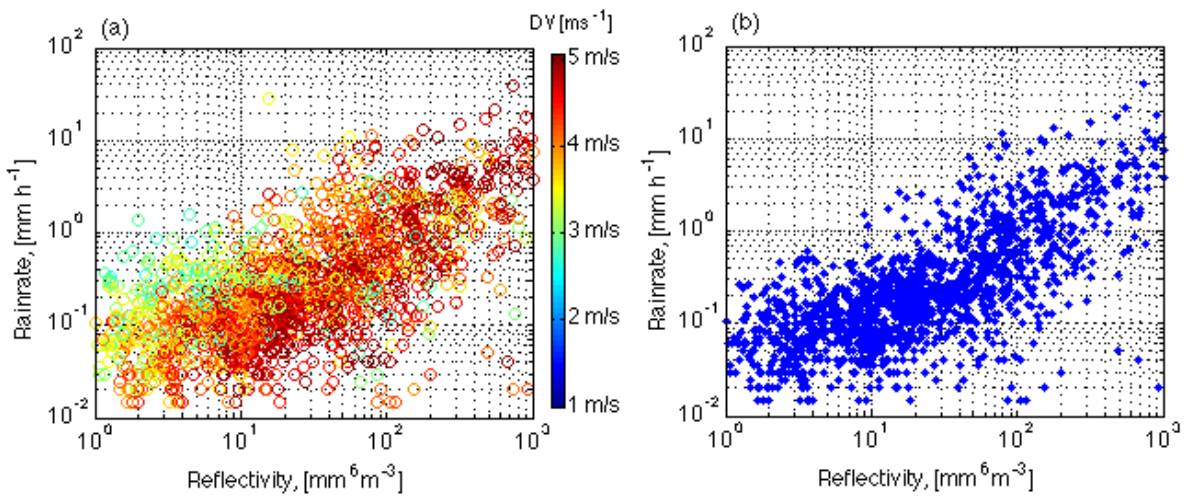

Figure 5. Scatter plots of rain rates $(R)$ observed from a video disdrometer vs. KAZR reflectivity values $\left(Z_{e}\right)$ averaged over a rain layer depth of $500 \mathrm{~m}$ as a function of KAZR Doppler velocities. (a) Before correction; (b) after constraining from Doppler velocity. The rain rates and KAZR reflectivity values corresponding to the KAZR Doppler velocities up to $5 \mathrm{~m} \mathrm{~s}^{-1}$ are only considered. The correlation coefficient and root mean square error before and after the correction are (0.495 vs. 0.606$)$ and (1.672 vs. 1.549), respectively.

118 out of 3098 total rain cases (i.e., 1 min rain profiles) identified in this study. For the selected profiles (2980 cases), the reflectivity changes due to microphysics were accounted for in the rain layer by subtracting the reflectivity change due to non-attenuation from the reflectivity change due to attenuation. For most rain cases considered here, the reflectivity changes due to attenuation were larger than those due microphysical changes by a factor of about 3-4 if the mean layer vertical Doppler velocity (DV) values in this layer were greater than $5 \mathrm{~m} \mathrm{~s}^{-1}$. Figure $4 \mathrm{a}$ and $\mathrm{b}$ show the profiles of reflectivity from the KAZR and S-PolKa as a function of surface rain rates from the optical rain gauge. For rain rates $>\sim 1 \mathrm{~mm} \mathrm{~h}^{-1}$, the KAZR shows lower reflectivity values compared to the S-PolKa (Fig. 4a), which is due to the attenuation and Mie effects for large drops at the Ka-band. The reflectivity profiles from both KAZR and S-PolKa attain maxima around $4.5 \mathrm{~km}$, which is due to the melting layer. For higher rain rates, reflectivity profiles from the KAZR have sharp gradients in the lower layers, which is mainly due to attenuation in the rain layer.

\subsection{2 $Z_{e}-R$ based rain rate estimation}

Here we describe a procedure to retrieve lighter rain rates based on the KAZR reflectivity measurements by applying the $Z_{e}-R$ relation computed from the disdrometer at Ka-band. Compared to high rain rates, radar signals in low rain rate precipitation are affected by attenuation less significantly. Thus, the absolute reflectivities during lighter rainfall can be used to infer rain rates. Here, Doppler velocity is used to separate lighter rain by selecting a threshold of $5 \mathrm{~m} \mathrm{~s}^{-1}$. The justification for the chosen threshold is discussed later. Figure 5a shows KAZR reflectivity values (averaged over a $500 \mathrm{~m}$ rain layer) and rain rates from the 2-DVD disdrometer corresponding to the Doppler velocities up to $5 \mathrm{~m} \mathrm{~s}^{-1}$. Reflectivity values exhibit skill for implementing a $Z_{e}-R$ relation, though there is considerable scatter. The non-linear 
Table 2. Statistics on data sample reduction, and mean and standard deviation of the Doppler velocity (DV) used to constrain the $Z_{e}-R$ relation as shown in Fig. 6. Outliers are removed for the Doppler velocities that are larger than the Doppler velocity bound (mean \pm 2 SD) for each reflectivity bin.

\begin{tabular}{lcccccc}
\hline Reflectivity range $\left(\mathrm{mm}^{6} \mathrm{~m}^{-3}\right)$ & $1-5$ & $5-10$ & $10-50$ & $50-100$ & $100-500$ & $500-1000$ \\
\hline Total no. of samples & 307 & 264 & 714 & 228 & 266 & 50 \\
No. of outliers & 48 & 59 & 169 & 47 & 64 & 11 \\
Mean DV $\left(\mathrm{m} \mathrm{s}^{-1}\right)$ & 3.63 & 4.21 & 4.46 & 4.3 & 4.46 & 4.6 \\
$1 \mathrm{SD}\left(\mathrm{m} \mathrm{s}^{-1}\right)$ & 0.53 & 0.40 & 0.36 & 0.43 & 0.40 & 0.34 \\
\hline
\end{tabular}

effects of evaporation might have on the $Z_{e}-R$ relation is to widen the $Z_{e}-R$ bound, which results in large errors in the retrieved rain rates. The increase in Doppler velocities with rain rates provides an additional constraint to remove some of these outliers and refine the $Z_{e}-R$ relation. For each reflectivity bin, the Doppler velocities have been sorted in an ascending manner and threshold bounds are defined by considering the mean and twice the standard deviation of Doppler velocities. The reflectivity values were removed if corresponding Doppler velocities in each bin exceeded the threshold bound (mean $\pm 2 \mathrm{SD}$ ). The reduction in number of data samples after applying the Doppler velocity constraint, and the thresholds (mean and SD) used for different reflectivity bins are listed in Table 2. Figure 5b shows the refined $Z_{e}-R$ relation after using Doppler velocities as a constraint. After applying the constraint, the correlation coefficient increased from 0.495 to 0.606 , and root mean square error (RMSE) is reduced from 1.672 to 1.549 . The Ka-band reflectivity values were computed from DSDs obtained from a video disdrometer using Mie calculations (Bohren and Hufman, 1983) as

$Z_{e h}=\lambda^{4} \pi^{-5}\left|\frac{\left(m_{\mathrm{w}}^{2}+2\right)}{\left(m_{\mathrm{w}}^{2}-1\right)}\right|^{2} \sum_{i}\left\langle\sigma_{h}\left(D_{e i}\right)\right\rangle n_{i}\left(D_{e i}\right)$,

where $m_{\mathrm{w}}$ is the complex refractive index of water, $\sigma_{h}\left(D_{e i}\right)$ the Mie backscatter cross section, $n_{i}\left(D_{e i}\right)$ the drop concentration in $i$ th diameter $\left(D_{e i}\right)$ bin of the disdrometer, and the summation is performed over the disdrometer size bins. The $Z_{e}-R$ relation based on KAZR observed reflectivity is compared with the computed reflectivity values using disdrometer data by fitting the power law (of the form $R=a Z_{e}^{b}$ ) (Fig. 6). The $Z_{e}-R$ relations were derived as in Martner et al. (2008) using a power-law regression approach (i.e., the linear regression in the logarithmic units of $\log \left(Z_{e}\right)$ and $\log (R)$, with $\log \left(Z_{e}\right)$ being an independent variable).

This approach provides a better representation of lighter rainfall for which absolute values of KAZR reflectivity are used to estimate $R$. While deriving the $Z_{e}-R$ relation, a lower cutoff threshold of $R>0.01 \mathrm{~mm} \mathrm{~h}^{-1}$ was employed as a tradeoff to eliminate lighter rain rate (and corresponding $Z_{e}$ ) points which are possibly noise contaminated and increase the sample size at the lower rain rate spectrum. The coefficients $\left(A=(1 / a)^{1 / b}\right)$ and exponents $(B=1 / b)$ of the proposed $Z_{e}-R$ relations from the KAZR and disdrometer

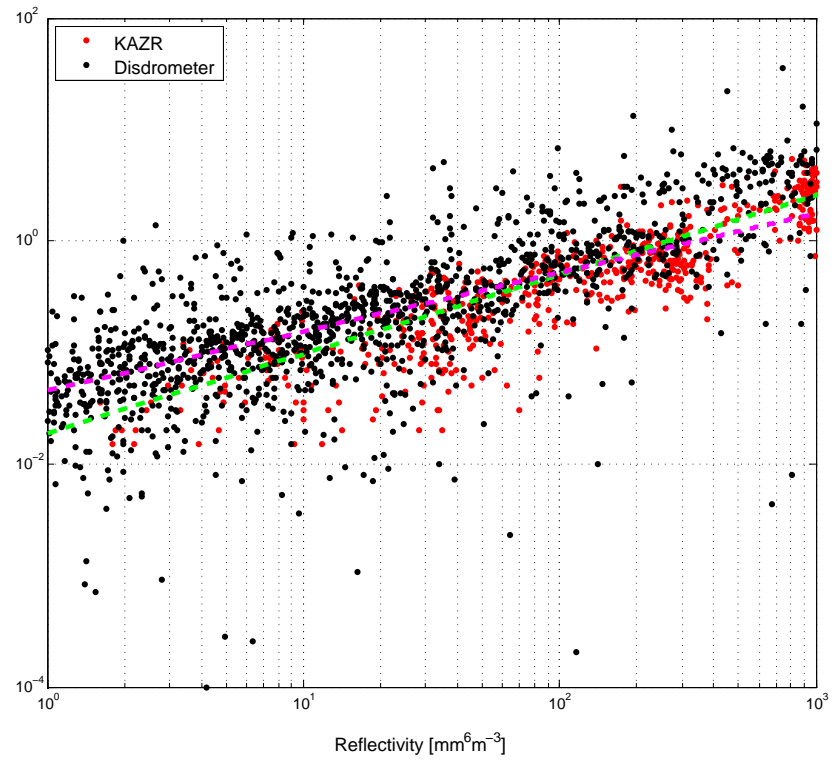

Figure 6. Comparison of $Z_{e}-R$ relationships based on the KAZR reflectivity, and computed reflectivity's at the Ka-band using disdrometer data. The green and magenta dashed lines indicate power laws ( $\mathrm{RR}=a Z^{b}$, where $a$ and $b$ are coefficient and exponent) fitted to the KAZR and disdrometer data, respectively. For the green line, $a=0.0112$ and $b=0.8469$. For the magenta line are $a=0.0267$ and $b=0.664$.

for stratiform and convective rain regimes are summarized in Table 3. The coefficient and exponents for the convective rain events derived from both KAZR and disdrometer data sets are slightly higher compared to stratiform rain events, and they are slightly lower for the KAZR compared to the disdrometer. For reflectivity range (up to $500 \mathrm{~mm}^{6} \mathrm{~m}^{-3}$ ), the KAZR rain rates are slightly lower compared to the disdrometer for a given reflectivity. Whereas, for the higher reflectivities (above $500 \mathrm{~mm}^{6} \mathrm{~m}^{-3}$ ), the KAZR reflectivities matches closely with the disdrometer values. The underestimate of the rain rates corresponds to the KAZR reflectivity range (up to $500 \mathrm{~mm}^{6} \mathrm{~m}^{-3}$ ) may be attributed to the reflectivity attenuation due to antenna/radome wetting, which we have not accounted in this study. The coefficients and exponents derived from this study are with in the range between 75 and 300 and 1.2 and 2.0 used in the operational $Z_{e}-R$ relations. The expo- 
Table 3. Coefficients $(a, A)$ and exponents $(b, B)$ in $Z-R$ relations derived from disdrometer and the KAZR for convective and stratiform rain events.

\begin{tabular}{llll|lll}
\hline & \multicolumn{3}{c|}{ Disdrometer } & \multicolumn{3}{c}{ KAZR } \\
\cline { 2 - 7 } & Total & Stratiform & Convective & Total & Stratiform & Convective \\
\hline$a$ & 0.0267 & 0.0240 & 0.0366 & 0.0112 & 0.0094 & 0.0192 \\
$b$ & 0.664 & 0.6847 & 0.6049 & 0.8469 & 0.901 & 0.7355 \\
$A=(1 / a)^{(1 / b)}$ & 233.76 & 232.21 & 236.64 & 202.07 & 177.03 & 215.80 \\
$B=1 / b$ & 1.50 & 1.46 & 1.65 & 1.18 & 1.11 & 1.35 \\
\hline
\end{tabular}

nent from the KAZR relation is slightly smaller $(B=1.18)$ compared to the values $(B=1.3-1.4)$ derived previously by Tokay et al. (2009) who used vertically pointing S- and Kaband radars with a collocated disdrometer. This can be attributed to the effect of attenuation for low rain rates, which is assumed to be negligible in the proposed $Z_{e}-R$ relation based on the KAZR.

\subsection{Choosing Doppler velocity threshold to separate rain regimes}

This section explains the basis for selecting a Doppler velocity threshold to separate two rain retrieval methods and sensitivity of the chosen Doppler velocity threshold on the overall performance of the rain rate retrieval.

The development of an automated Ka-band radar algorithm for the rain rate depends on the proper identification of the dominant mechanisms that control the profile of radar reflectivity $Z_{e}$, (dBZ: decibels of $\mathrm{mm}^{6} \mathrm{~m}^{-3}$ ) and its gradient $\frac{\Delta Z_{e}}{\Delta h}\left(\mathrm{~dB} \mathrm{~km}^{-1}\right)$, where $h$ is height. In light rain, the evolution of the drop size distribution (DSD) via different microphysical processes (accretion above the cloud base, evaporation below the cloud base) has a non-negligible impact on the profile of radar reflectivity $Z_{e}$. In this case, the use of specific attenuation $A\left(\mathrm{~dB} \mathrm{~km}^{-1}\right)$ estimates for rain rate retrievals can lead to larger errors (Matrosov, 2005) and the rain rate $R$ should be estimated from attenuation-corrected reflectivity values using a proper $Z_{e}-R$ relation.

Given that reflectivities are corrected for gaseous attention, the vertical gradient of radar reflectivity in the liquid hydrometeor layer can be expressed as

$$
\frac{\Delta Z_{e_{\mathrm{dBZ}}}}{\Delta h}=-2\left(A_{\mathrm{r}}+A_{\mathrm{c}}\right)+\left.\frac{\Delta Z_{e_{\mathrm{dBZ}}}}{\Delta h}\right|_{\mathrm{PRC}},
$$

where $A_{\mathrm{r}}$ and $A_{\mathrm{c}}$ are the one-way specific attenuations by rain liquid water and cloud respectively, and $\left.\frac{\Delta Z_{e_{\mathrm{dBZ}}}}{\Delta h}\right|_{\mathrm{PRC}}$ is the induced vertical gradient of the reflectivity due to two microphysical processes (e.g., accretion above the cloud base and evaporation below the cloud base) during the liquid precipitation (PRC). In this study, a simple 1-dimensional steady state microphysical model that accounts for accretion of cloud droplets and raindrop evaporation below the cloud base is used to investigate the sensitivity of $\frac{\Delta Z_{e_{\mathrm{dBZ}}}}{\Delta h}$ to ei- ther microphysical processes or radar signal attenuation by clouds and rain. A full bin-resolving microphysical calculations form the model. The raindrop population at the upper levels is assumed to follow the three-parameter DSD represented by two-parameter normalized gamma function and concentration parameter (Illingworth and Blackman, 2002):

$$
\begin{aligned}
N(D) & =\left[\frac{N_{w} \cdot 0.033 \cdot(3.67+\mu)^{\mu+4}}{\Gamma(\mu+4)}\left(\frac{D}{D_{o}}\right)^{\mu}\right] \\
& \cdot \exp \left[-(3.67+\mu) \frac{D}{D_{o}}\right],
\end{aligned}
$$

where $N(D)$ is the drop concentration $\left(\mathrm{m}^{-3}\right), N_{w}$ is the normalized intercept $\left(\mathrm{m}^{-3} \mathrm{~mm}^{-1}\right)$ and $\mu$ is the shape parameter. $D_{o}$ is the median volume diameter. 501 raindrop size bins, regularly spaced, represent the DSD extending up to equivalent drop diameter of $6 \mathrm{~mm}$. This equation reduces to $N(D)=N_{o} \cdot \exp (-\lambda D)$ for $\mu=0$.

A combination of three values of the shape parameter $\mu$ and four values of the normalized concentration parameter $N_{w}$ are used here for modeling. The parameterization of the microphysical processes (including sedimentation, accretion and evaporation) is drop size dependent and can be used to simulate liquid precipitation ranging from very light drizzle to heavy rainfall. The profiles of temperature, vertical air motion and relative humidity in the subcloud layer, and liquid water content in the cloud layer are fixed with no feedback from microphysical processes. This is because the microphysical processes (accretion and evaporation) that modify raindrop sizes conserve the raindrop flux with respect to number concentration (neglecting eventual complete evaporation of smallest rain drops), which results in vertical gradient of unattenuated reflectivity independent of the DSD concentration parameter. It is assumed that besides sedimentation, accretion and evaporation are the only active processes. The details of the parameterization of accretion and evaporation in the model are described in Kollias et al. (2011).

Figure 7 shows the model vertical gradient of reflectivity due to accretion, evaporation and attenuation by neglecting the vertical air motion. Thus, the Doppler velocity represents the reflectivity-weighted velocity of raindrop population. In these conditions, the computations shown in Fig. 7 can be representative for any type of rainfall. Above the cloud base, 


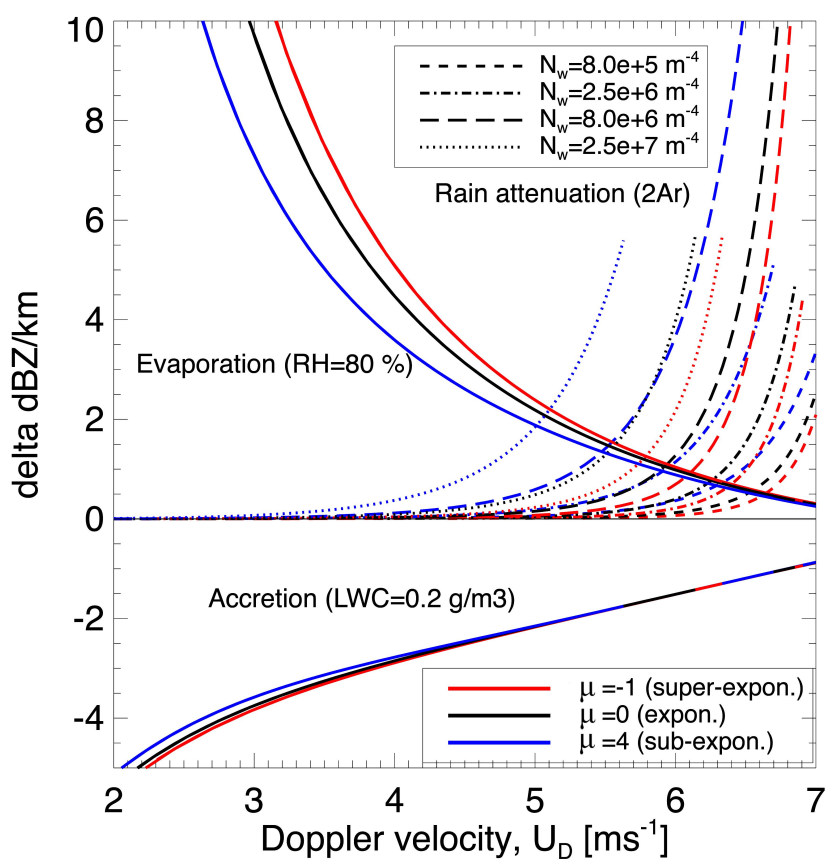

Figure 7. Theoretical curves of the reflectivity gradients vs. the Doppler velocities at the Ka-band frequency for different rain parameters. $N_{\mathrm{w}}$ and $\mu$ are normalized intercept and shape parameters of the gamma-function distribution. The solid lines (above zero) indicate reflectivity gradient changes due to evaporation on raindrops for various Doppler velocities assuming $\mathrm{RH}=80 \%$. The dotted and dashed lines (above zero) indicate changes in reflectivity gradients due to attenuation from raindrops for various Doppler velocities. The solid lines below zero indicate reflectivity gradient changes due to accretion above the cloud base. Different line colors indicate rain drop size distributions with different shape parameters, while line types indicate different normalized intercept parameters.

a cloud liquid water content amount of $0.2 \mathrm{~g} \mathrm{~m}^{-3}$ is assumed to be constant with height to estimate the change in the vertical gradient of the radar reflectivity due to accretion. Below the cloud base, a relative humidity of $80 \%$ is assumed to investigate the impact of evaporation on the observed vertical gradient of the radar reflectivity.

As expected, for mean Doppler velocity less than about $5 \mathrm{~m} \mathrm{~s}^{-1}$, the microphysical processes that can affect the evolution of the rain DSD with height are the main contributors to the observed vertical gradient of the radar reflectivity. At mean Doppler velocities higher than $5 \mathrm{~m} \mathrm{~s}^{-1}$, attenuation is the primary contributor to the observed $Z_{e}$ profile and can be used to extract the rain rate. All the calculations for raindrops pertinent to Fig. 7 are done using the Mie theory with accounting for rain attenuation. The attenuation by liquid water cloud is proportional to the cloud liquid water content with the proportionality factor being temperature-dependent (Matrosov et al., 2004). The cloud liquid attenuation is typically much smaller than that of rain for moderate and higher rain rates. A variable correction for attenuation due to oxy- gen and water vapor (Liebe et al., 1991) was implemented in the model calculations using the sounding data.

KAZR-based rain rate retrievals suggested here imply the use of two techniques for the two categories of rain rates. For low rain rate cases, which are characterized by Doppler velocities of equal or less than $5 \mathrm{~m} \mathrm{~s}^{-1}$, the $Z_{e}-R$ relation is applied. For rainfall with DV exceeding $5 \mathrm{~m} \mathrm{~s}^{-1}$, the attenuation-based technique is applied. Though choosing a DV threshold of $5 \mathrm{~m} \mathrm{~s}^{-1}$ based on 1-dimensional microphysical model results would seem to be a reasonable choice for separating two regimes $\left(A-R\right.$ and $\left.Z_{e}-R\right)$, they are not clearly separated in Fig. 7. This may lead to different retrievals for different selection of the DV threshold. Therefore, the sensitivity of choosing different thresholds on rain rates retrieved from both the $Z_{e}-R$ and $A-R$ (for $\mathrm{DV}>\mathrm{DV}_{\text {threshold }}$ ) techniques are tested for different Doppler velocity thresholds $\left(3,5\right.$, and $\left.7 \mathrm{~m} \mathrm{~s}^{-1}\right)$. For each set of selected Doppler velocity thresholds, $A-R$ technique is applied for $\mathrm{DV}>\mathrm{DV}_{\text {threshold }}$ and the $Z_{e}-R$ relations based on the disdrometer and the KAZR are separately applied for DV $<=\mathrm{DV}_{\text {threshold }}$. The retrieved rain rates from the KAZR are compared with the observed rain rates from the optical rain gauge (Fig. 8). It was found that the correlation coefficient between rain gauge and KAZR retrieved rain rates marginally increase from 0.56 to 0.70 for an increase in Doppler velocity threshold from 3 to $5 \mathrm{~m} \mathrm{~s}^{-1}$, and then slightly decreases $(0.70$ and $0.66)$ for higher Doppler velocity threshold. For the same Doppler velocity threshold (DV $=5 \mathrm{~m} \mathrm{~s}^{-1}$ ), the correlation coefficient between rain rates retrieved from the KAZR improved marginally from 0.62 to 0.7 for $Z_{e}-R$ based on disdrometer compared to the one based on the KAZR. This confirms that the Doppler velocity threshold of $5 \mathrm{~m} \mathrm{~s}^{-1}$ might be a logical choice for separating the two regimes with dominant microphysical effects and dominant attenuation effects for applying $Z_{e}-R$ and $A-R$ techniques respectively.

\section{Rain rates and rain amount}

\subsection{Rain rate comparison}

Applying the disdrometer-based $Z_{e}-R$ relation and $A-R$ techniques in two stages retrieves the continuous rain rates from the KAZR. Figure 9 compares the time series of retrieved rain rates from the KAZR with that based on the rain gauge measurement at $1 \mathrm{~min}$ resolution. The comparison of the time series is separately shown for the stratiform and convective rain events (Fig. 9a). Given the rudimentary treatment of the uncertainties in this study, the good agreement of the trend justifies the scope to use the KAZR measurements for continuous retrievals of rain rates. The time series are further separated based on the method used to derive the rain rates (Fig. 9b). The agreement of the rain rates retrieved from the $A-R$ method are slightly better compared to the rain rates derived from the $Z_{e}-R$ method. Some of the underestimated 

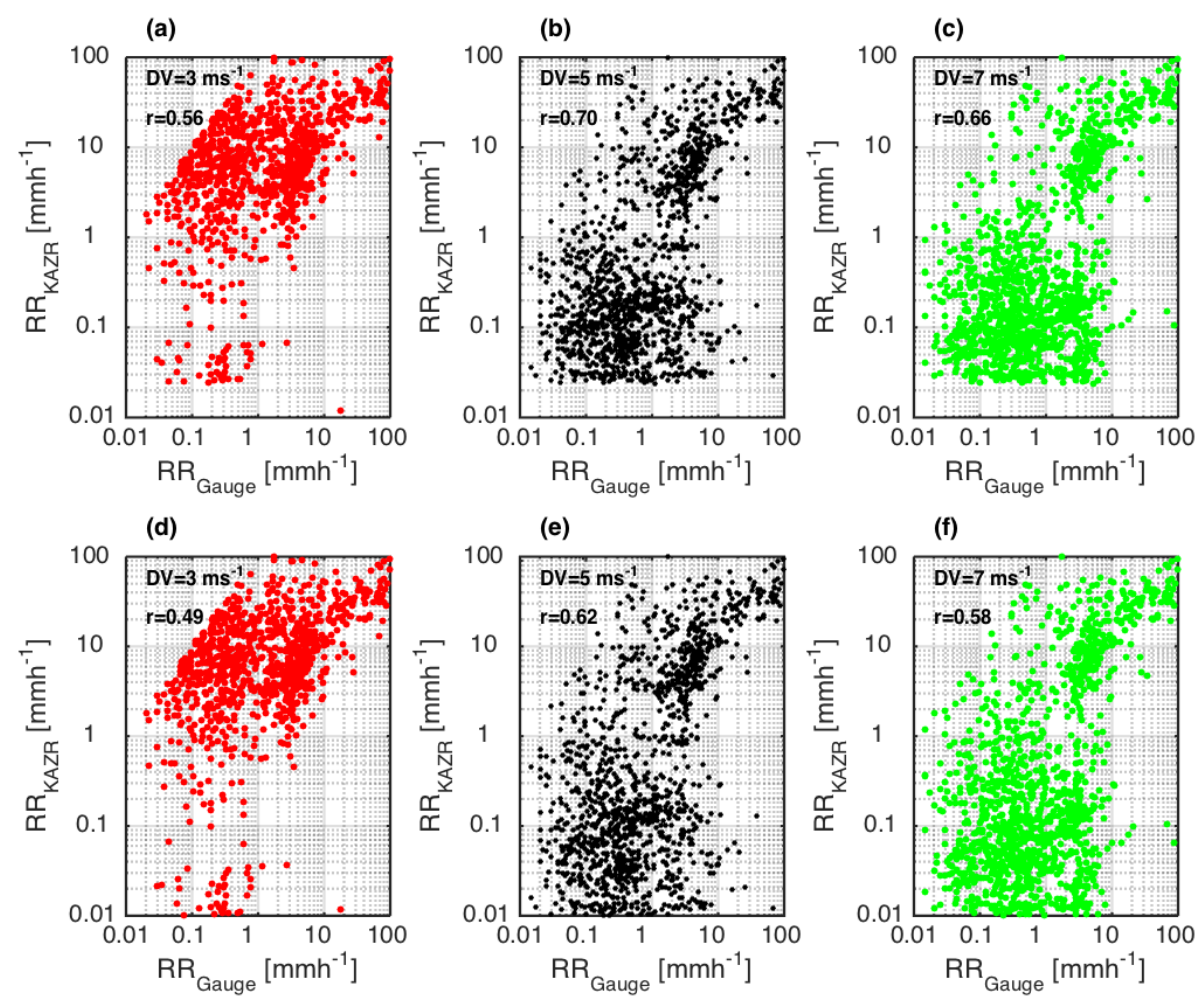

Figure 8. Scatter plot of observed rain rates from an optical gauge vs. rain rates retrieved from the KAZR using the $Z_{e}-R$ relations developed from the disdrometer $(\mathbf{a}-\mathbf{c})$ and the KAZR $(\mathbf{d}-\mathbf{f})$ for different Doppler velocity thresholds $\left(\mathrm{DV}_{\text {thresh }}\right)$. The samples covering 15 days of rain events between 8 October 2011 and 6 February 2012. Rain rates from the KAZR are retrieved using both $Z_{e}-R$ (for DV $<=D V_{\text {thresh }}$ ) and $A-R$ (for $\mathrm{DV}>\mathrm{DV}_{\text {thresh }}$ ) methods for different Doppler velocity thresholds $\left(3,5\right.$, and $7 \mathrm{~m} \mathrm{~s}^{-1}$ ) shown in the legend. The $Z_{e}-R$ relations are applied separately for the stratiform and convective rain events. The list of $Z_{e}-R$ coefficients and exponents for different rain types are summarized in Table 3.
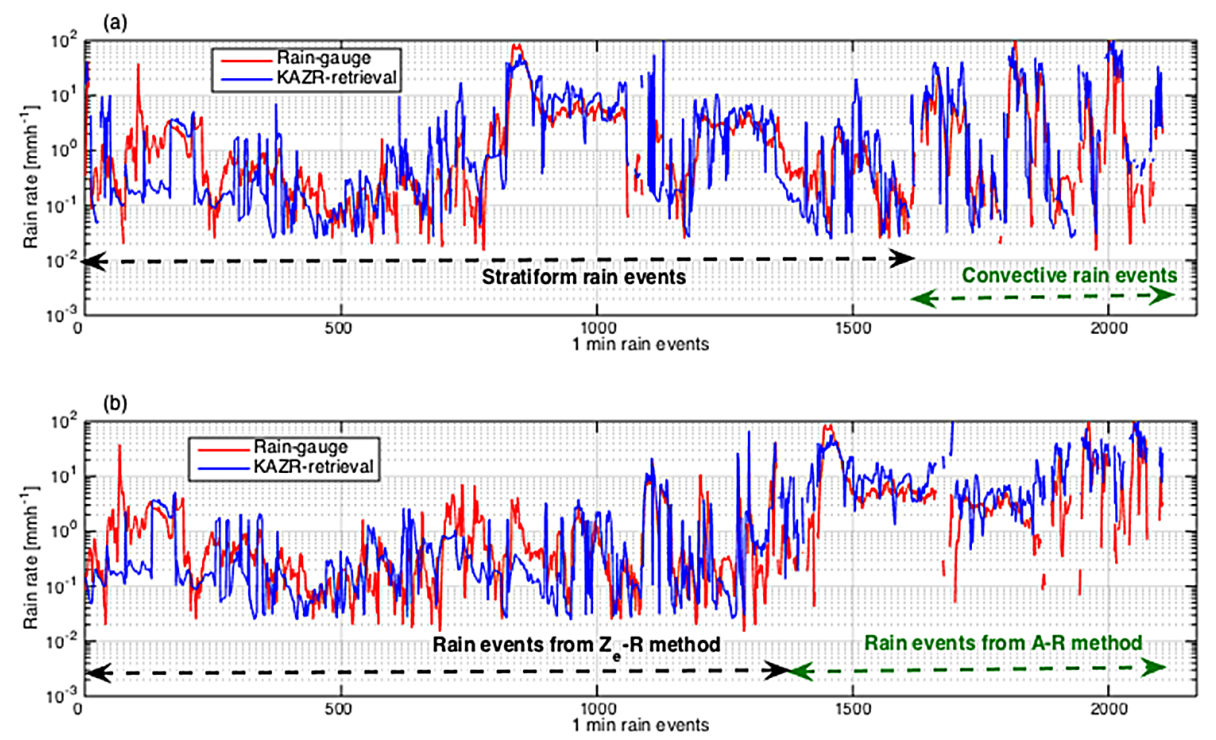

Figure 9. Time series of 1 min averaged rain rates from the KAZR and a rain gauge covering 15 days of rain events between 8 October 2011 and 6 February 2012. (a) Rain rates are separated based on the regime type: stratiform (up to 1614 min) and convective (1615-2168 min) rain cases. (b) Rain rates are separated based on the method used to derive rain rates: $Z_{e}-R$ relationship (for DV $<=5 \mathrm{~m} \mathrm{~s}-1$; up to $1344 \mathrm{~min}$ ) and $A-R$ relationship (for DV $>5 \mathrm{~m} \mathrm{~s}^{-1} ; 1345-2168 \mathrm{~min}$ ). 

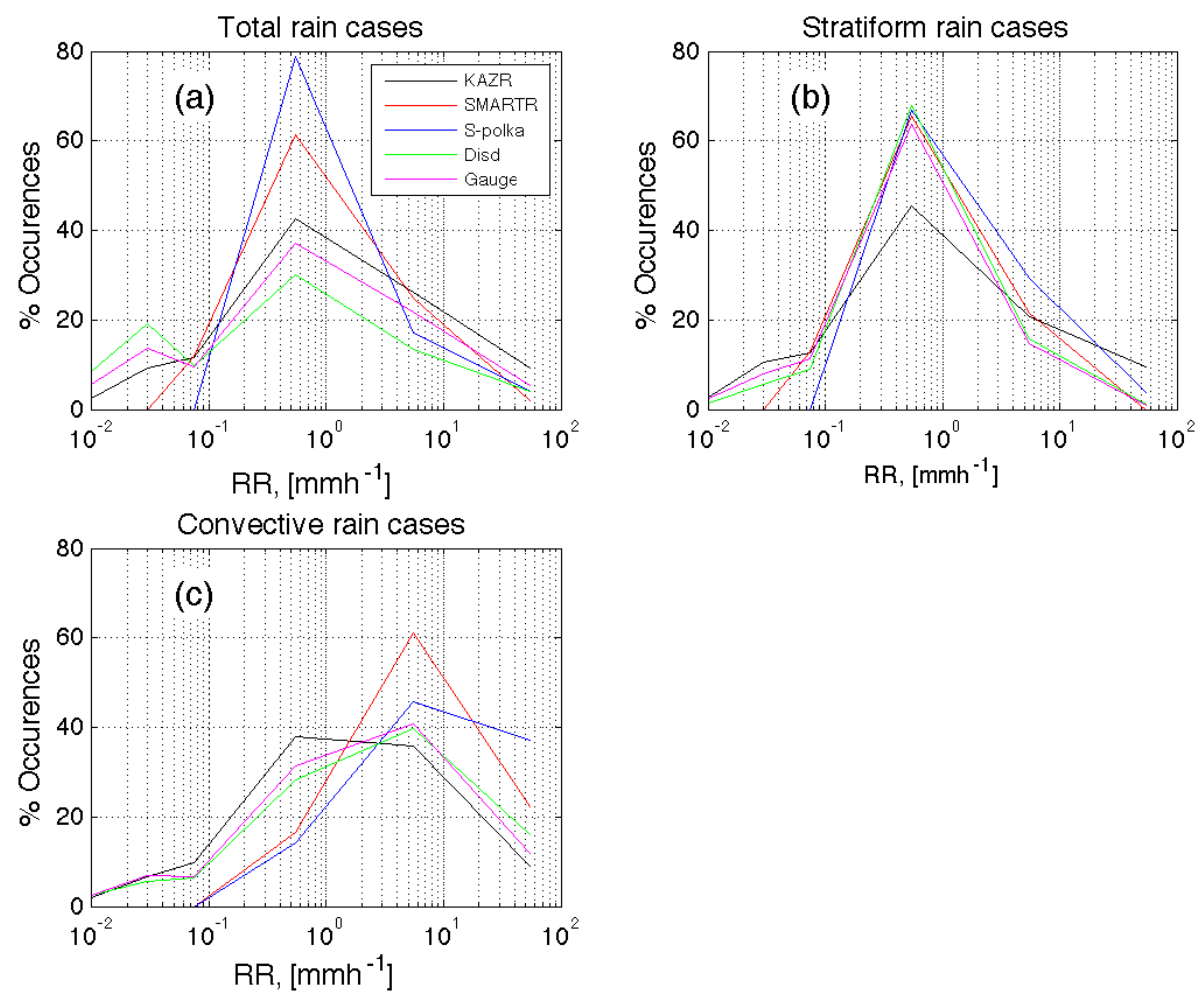

Figure 10. Histograms of rain-rates from the KAZR, SMART-R, S-PolKa, optical rain gauge, and 2-dimensional video disdrometer for (a) total rain cases, (b) stratiform rain cases, and (c) convective rain cases.

$Z_{e}-R$ estimated rain rates from the KAZR might be resulted from the reflectivity attenuation due to antenna/radome wetting, which we have not accounted for in this study.

Figure 10 shows the comparison of histograms of rain rates retrieved from the KAZR, S-PolKa and Smart-R, rain gauge and 2-DVD instruments for three rain categories (stratiform, convective and total) respectively. The S-PolKa and SMART-R retrievals used the relation $Z_{e}=178 R^{1.44}$, which was derived using disdrometer data collected from the Addu Atoll site. The stratiform vs. convective rain rates are classified from KAZR bright band signatures near the melting layer from the KAZR. The detection of the bright band is done following the methodology explained in (Geerts and Dawei, 2004). The rain rate histograms between the different radars exhibit common features: the convective rain cases are skewed towards higher rain rates compared to the stratiform rain cases. The peak of the stratiform rain PDF from the KAZR coincides with the other estimates, whereas the peak of the convective rain PDF is slightly shifted towards lower rain rates. Also, KAZR rain retrievals have slightly more occurrences of higher rain rates for stratiform events and slightly less occurrence of higher rain rates for convective events. The observed differences can also be attributed to the factors such as instrument uncertainties, sampling volume differences between the rain gauge and radars, uncertainties associated with the assumptions (e.g., effect of wind shear, neglecting vertical wind, etc.), and the uncertainties associated with the $A-R$ and $Z_{e}-R$ techniques.

\subsection{Difference in the rain amount}

Rain retrievals are performed from the KAZR for the events, which satisfy the criteria needed for applying $Z_{e}-R$ and $A-$ $R$ techniques, which resulted in eliminating 562 rain events, where there are no rain retrievals. In order to calculate the total rain accumulation, one needs to have continuous rain rate retrievals. Gaps (due to outliers) in the rain rate retrievals would lead to underestimation in the total rain accumulation.

Here, we have estimated the rain accumulation from the rain gauge and the KAZR using for the rain events when data from both the instruments are available. Unless we do so, comparing rain accumulation between them may not be consistent. For this reason, we have selected 2168 cases (out of the 2582 valid retrievals) where data from both KAZR and rain gauge data are available. The rain accumulation from the KAZR and rain gauge using overlapped cases are 162.63 and $155.75 \mathrm{~mm}$ respectively. Compared to rain gauge, the KAZR slightly overestimates the rain amount with a difference of $6.88 \mathrm{~mm}$ and a bias of $4.42 \%$. The rain accumulation and the bias in KAZR rain amounts are further decomposed separately for the convective and stratiform cases (Table 4). Although the difference in the total (stratiform + convective) rain accumulation between them is smaller, it is relatively 
Table 4. Rain accumulation from the KAZR and optical rain gauge for the stratiform, convective, and total (stratiform + convective) rain events when data from both the instruments are available. Rain events covering over 15 days between 8 October 2011 and 6 February 2012 for the events Bias in the rain amount from the KAZR is given in italic.

\begin{tabular}{lccc}
\hline & $\begin{array}{c}\text { Rain accumulation, mm } \\
\text { (stratiform + convective) }\end{array}$ & $\begin{array}{c}\text { Rain accumulation, mm } \\
\text { (stratiform) }\end{array}$ & $\begin{array}{c}\text { Rain accumulation, mm } \\
\text { (convective) }\end{array}$ \\
\hline $\begin{array}{l}\text { Rain accumulation from rain gauge when both } \\
\text { gauge and valid KAZR data available } \\
\text { (no. of 1 min cases used: 268) }\end{array}$ & 155.75 & 112.41 & 43.34 \\
$\begin{array}{l}\text { Rain accumulation from KAZR when both } \\
\text { gauge and valid KAZR data available } \\
\text { (no. of 1 min cases used: 2168) }\end{array}$ & 162.63 & 125.93 & 36.7 \\
$\begin{array}{l}\text { Difference in KAZR rain accumulation and } \\
\text { bias (in \%) }\end{array}$ & 6.88 & 13.52 & 6.64 \\
\end{tabular}

larger and compensating for the stratiform and convective cases. The KAZR rain accumulation from the stratiform rain cases slightly larger (125.93 over $112.41 \mathrm{~mm}$ with a bias of $12.03 \%$ ) than the gauge accumulation, whereas for the convective cases, it is slightly smaller (36.7 over $43.34 \mathrm{~mm}$ with a bias of $15.32 \%$ ) than the gauge accumulation. The contribution of the removed outliers (118 cases: which have dominant microphysical effects) to the rain accumulation is about $8 \%$, which would be an additional error in the rain accumulation if microphysical effects are neglected. The differences could be larger (about 10-15\%) if accumulations are considered separately for stratiform and convective cases). 398 cases have been removed as the outliers while constraining the $Z_{e}-R$ relation using Doppler velocity as a constraint. If we include these outliers for the rain retrieval, there is a bias of $4 \%$ in the rain accumulation. If we use KAZR-based $Z_{e}-$ $R$ relation instead of $Z_{e}-R$ relation based on the disdrometer, the difference in rain accumulation compared to gauge accumulation would be about 7.8 instead of $4.5 \%$.

\section{Limitations and uncertainties}

The uncertainties in the rain rate retrievals arise from such factors as the natural variability of drop size distributions, orientation of rainfall fall streaks, radar calibration (when using $Z_{e}-R$ relations), and vertical air motions influencing Doppler velocity measurements.

The wind shear can produce non-vertical fall streaks (also known as a wind-drift/dynamic effect) of precipitation. This effect is usually more pronounced for snow and ice particle regions compared to the rainfall because of their much smaller terminal velocities. The treatment of the non-vertical fall streaks is discussed by Mittermaier et al. (2004). Significant wind-drift leads to strong positive and negative reflectivity gradient artifacts, which can be seen from the reflectivity data. The wind-drift errors are caused by both wind shear and wind advection. The extent to which wind-drift effects influence precipitation retrievals depends on the terminal velocity of the raindrops and the location and depth of the rain layer chosen for retrievals.

The events with non-vertical fall streaks caused by wind shear can also be recognized from the measurement of vertical profiles of reflectivity at longer wavelength radars. Such measurements are available, for example, during vertical scans of the S-PolKa and Smart-R radar measurements in DYNAMO. Those estimates of non-attenuated profiles can be used - to either reject strong non-attenuated reflectivity gradient cases or to account for actual non-attenuated reflectivity profiles in Ka-band retrievals after correction for frequency differences as was suggested, for example, in Matrosov (2010).

The wind-drift effects can significantly affect retrievals of lower rain rates where raindrops are smaller. By averaging the Doppler velocities over $1 \mathrm{~min}$, we have partly mitigated these dynamic effects. The winds (averaged over the depth of the rain layer) and wind shear values (difference between top and bottom of the rain layer) are calculated for the rain events from the nearest soundings. The average wind speed and wind shear values observed for the rainy days considered here were $\sim 5.1 \pm 1.8$ and $3.5 \pm 2.1 \times 10^{-3} \mathrm{~m} \mathrm{~s}^{-1}$ respectively. The wind shear effects were not significant as it is shown from the nearest soundings and also confirmed from the SMART-R and S-PolKa data sets. Some potential future approaches to identify possible strong wind shear effects when scanning radars are not available include the use of interpolated wind information from soundings or measurements from wind profilers (if available).

In implementing the two different techniques for retrieving rain rates continuously, a threshold on Doppler velocity, which is used as a proxy for fall velocity, is utilized to separate lighter and heavier precipitation. It is assumed that vertical air motions are on average small compared to fall velocities. Though this assumption may be reasonable for stratiform rain conditions after time averaging (1 min here), the presence of strong vertical air motions during convective cases may lead to wrong separation of the regimes when either attenuation or microphysical effects on observed $\mathrm{Ka}$ - 
band reflectivity profiles are dominant. The simultaneous retrieval of precipitation parameter and vertical velocity from Doppler radar spectra using VHF profiler data is discussed in Wakasugi et al. (1986). Since DYNAMO offers no such setup for combined retrievals of precipitation and vertical velocity, no treatment of vertical wind was considered in the present study.

Another issue that needs careful assessment is the variability, correction and representativeness of the $Z_{e}-R$ relation proposed in this study. The present study proposed a $Z_{e}-R$ relation for the Ka-band using Doppler velocity as a constraint. Though the rain rate correction is proposed to account for attention when the $Z_{e}-R$ relation is used for retrievals, its practical implementation to other regions, seasons and different rain conditions needs to be tuned and the deviations resulted from the radar calibration needs to be accounted. The attenuation of the reflectivity at Ka-band when the radome/antenna is wet is not non-negligible and not accounted for in this study. This results in some of the $Z_{e}-R$ based rain estimates being substantially underestimated. To refine the methodology and improve the corrections proposed here further investigations using previous field experimental data sets and/or collocated Ka-band and precipitation radar observations is required.

\section{Summary and conclusions}

An automated algorithm is developed to retrieve rain rates from vertically pointing Ka-band radar measurements. To the best knowledge of the authors, this is first attempt to extend KAZR observations for routine rain rate retrievals. The proposed algorithm uses two different methods for estimating rain rates. For high Doppler velocities (DV $>5 \mathrm{~m} \mathrm{~s}^{-1}$, the $A-R$ relation is applied. For lower Doppler velocities $\left(\mathrm{DV}<=5 \mathrm{~m} \mathrm{~s}^{-1}\right.$ ), the $Z_{e}-R$ relation is applied. A 1dimensional microphysical model that accounts for the microphysical processes of accretion and evaporation, and radar attenuation due to liquid is used to infer the criteria for determining if microphysics or attenuation controls the observed vertical profiles of KAZR reflectivity. $Z_{e}-R$ relations based on the KAZR and disdrometer data at Ka-band is proposed. The proposed algorithm is applied to 4 months of KAZR observations collected during the deployment of the ARM Mobile Facility during the DYNAMO/AMIE field campaign.

Collocated observations from the S-PolKa radar is used to identify the rainy profiles where microphysical effects are dominant over rain layer attenuation effects. Out of 3149 rain cases, 118 had dominant microphysical effects during the period of observations. Failing to separate them would result in the bias of $8 \%$ in the total rain amount in addition to the difference contributing from the outliers and also due to uncertainty in the rain retrieval technique. Bias in the total rain accumulation would slightly larger $(\sim 7.8 \%)$ if we use KAZRbased $Z_{e}-R$ relation compared to $Z_{e}-R$ relation based on the disdrometer $(4.5 \%)$. Compared to rain gauge, the rain amount from the KAZR slightly overestimates with a difference of $6.88 \mathrm{~mm}$ and a bias of $4.42 \%$. By separating the contributions of total rain accumulation into stratiform and convective rain accumulations, it was found that the stratiform rain accumulation from the KAZR is slightly larger (125.93 over $112.41 \mathrm{~mm}$ ) gauge accumulation, whereas the convective rain accumulation from the KAZR is slightly smaller ( 36.7 over $43.34 \mathrm{~mm}$ ) compared to the gauge accumulation.

The KAZR retrieved rain rate time series are compared with the nearby surface rain gauge measurements. The comparison shows a good agreement. The statistics of the KAZR retrieved rain rates, observed rain rates from the gauge and disdrometer, and those derived from the S-PolKa and SMART-R data are decomposed for stratiform, convective, and total rain events. The peak of the stratiform rain rate PDF from the KAZR coincides with the other measurements, whereas the peak of the convective rain PDF is slightly shifted towards lower rain rates. Also, KAZR rain retrievals have slightly more occurrences of higher rain rates for stratiform events and slightly less occurrence of higher rain rates for convective events.

The present study sets a framework for retrieving rainfall rates from vertically pointing Ka-band radars using an algorithm with a physical basis. This algorithm will be applied to retrieve rain rates at the other ARM sites to study shallow to deep convection transitions and related microphysical processes.

Given that the Ka-band radars are deployed at many permanent and mobile facilities as part of the ARM program throughout the world and also at several research institutions in Europe (e.g., MIRA-36 cloud radars), such estimates would be useful in future applications especially for observational sites when retrievals from more conventional approaches that utilize lower frequency (e.g., X-, C-, or S-band) scanning radar measurements are unavailable or limited in time or vertical resolution (e.g., due to remoteness of scanning radar locations).

Though we have focused our study on retrieving only layer-average rain rates, it has the potential scope for providing vertically resolved information, which is one of the potential advantages of using zenith-looking radar compared to more direct ground based sensor estimates from gauge or disdrometer. The presented technique will be applied to other ARM sites (Manus, Darwin and Southern Great Plains) where there is KAZR and surface rain observations are available. 
Acknowledgements. We would like to thank Zhe Feng from Pacific Northwest National Laboratory for sharing the merged radar data for the DYNAMO period. This study was supported by DOE ASR Grant ER65283.

Edited by: M. Portabella

\section{References}

Aydin, K. and Daisley, S. E. A.: Relationships between rainfall rate and $35 \mathrm{GHz}$ attenuation and differential attenuation: modeling the effects of raindrop size distribution, canting, and oscillation, IEEE T. Geosci. Remote, 40, 2343-2351, 2002.

Bohren, C. F. and Huffman, D. R.: Absorption and Scattering of Light by Small Particles, Wiley, New York, USA, 530 pp., 1983.

Feng, Z., McFarlane, S. A., Schumacher, C., Ellis, S., and Bharadwaj, N.: Constructing a merged cloud-precipitation radar dataset for tropical convective clouds during the DY- NAMO/AMIE Experiment at Addu Atoll, J. Atmos. Ocean. Technol., 31, 10211042, doi:10.1175/JTECH-D-13-00132.1, 2014.

Geerts, B. and Dawei, Y.: Classification and characterization of tropical precipitation based on high-resolution airborne vertical incidence radar, Part I: Classification, J. Appl. Meteorol., 43, 1554-1566, 2004.

Huffman, G. J., Bolvin, D. T., Nelkin, E. J., Wolff, D. B., Adler, R. F., Gu, G., Hong, Y., Bowman, K. P., and Stocker, E. F.: The TRMM Multisatellite Precipitation Analysis (TMPA): quasiglobal, multiyear, combined-sensor precipitation estimates at fine scales, J. Hydrometeorol., 8, 38-55, 2007.

Illingworth, A. J. and Blackman, T. M.: The need to represent raindrop size spectra as normalized gamma distributions for the interpretation of polarization radar observations, J. Appl. Meteorol., 41, 286-297, 2002.

Kollias, P., Clothiaux, E. E., Miller, M. A., Albrecht, B. A., Stephens, G. L., and Ackerman, T. P.: Millimeter-wavelength radars: new frontier in atmospheric cloud and precipitation research, B. Am. Meteorol. Soc., 88, 1608-1624, doi:10.1175/BAMS-88-10-1608, 2007.

Kollias, P., Szyrmer, W., Remillard, J., and Luke, E.: Cloud radar Doppler spectra in drizzling stratiform clouds, Part II: Observations and microphysical modeling of drizzle evolution, J. Geophys. Res.-Atmos., 116, D13203, doi:10.1029/2010JD015238, 2011.

Kruger, A., and Krajewski, W.: Two-dimensional video disdrometer: A description, J. Atmos. Oceanic Technol., 19, 602-617, doi:10.1175/1520-0426(2002)019<0602:TDVDAD>2.0.CO;2, 2002.

Kummerow, C., Barnes, W., Kozu, T., Shiue, J., and Simpson, J.: The Tropical Rainfall Measuring Mission (TRMM) sensor package, J. Atmos. Ocean Tech., 15, 809-817, 1998.

Lhermitte, R.: Attenuation and scattering of millimeter wavelength radiation by cloud and precipitation, J. Atmos. Ocean Tech., 7, 464-479, 1990.

Lebsock, M. D. and L'Ecuyer, T. S.: The retrieval of warm rain from CloudSat, J. Geophys. Res., 116, D20209, doi:10.1029/2011JD016076, 2011.
Liebe, H. J., Huffort, G. A., and Manage, T.: A model for the complex permittivity of water at frequencies below $1 \mathrm{THz}$, Int. J. Infrared. Milli., 12, 659-675, 1991.

Marshall, J. S. and Palmer, W. Mc K.: The distribution of raindrops with size, J. Meteor., 5, 165-166, 1948.

Mather, J. H. and Voyles, J. W.: The ARM Climate Research Facility: a review of structure and capabilities, B. Am. Meteorol. Soc., 94, 377-392, doi:10.1175/BAMS-D-11-00218.1, 2013.

Martner, B. E., Yuter, S. E., White, A. B., Matrosov, S. Y., Kingsmill, D. E., and Ralph, F. M.: Raindrop size distributions and rain characteristics in California-coastal rainfall for periods with and without a radar bright band, J. Hydrometeor., 9, 408425, 2008.

Matrosov, S. Y.: Attenuation-based estimates of rainfall rates aloft with vertically pointing Ka-band radars, J. Atmos. Ocean Tech., 22, 43-54, 2005.

Matrosov, S. Y.: Potential for attenuation-based estimations of rainfall rate from CloudSat, Geophys. Res. Lett., 34, L05817, doi:10.1029/2006GL029161, 2007.

Matrosov, S. Y.: Synergetic use of millimeter- and centimeterwavelength radars for retrievals of cloud and rainfall parameters, Atmos. Chem. Phys., 10, 3321-3331, doi:10.5194/acp-10-33212010, 2010.

Matrosov, S. Y., Uttal, T., and Hazen, D. A.: Evaluation of Radar Reflectivity-Based Estimates of Water Content in Stratiform Marine Clouds, J. Appl. Meteor., 43, 405-419, 2004.

Matrosov, S. Y., May, P. T., and Shupe, M. D.: Rainfall profiling using Atmospheric Measurement Program vertically pointing 8 mm wavelength radars, J. Atmos. Ocean Tech., 23, 1478-1491, 2006.

Mittermaier, M. P., Hogan, R. J., and Illingworth, A. J.: Using mesoscale winds for correcting wind-drift errors in radar estimates of surface rainfall, Q. J. Roy. Meteor. Soc., 130, 21052123, 2004.

Rajopadhyaya, D. K., May, P. T., Cifelli, R., Avery, S. K., Williams, C. R., Ecklund, W. L., and Gage, K. S.: The effect of vertical air motions on rain rates and median volume diameter determined from combined UHF and VHF wind profiler measurements and comparisons with rain gauge measurements, J. Atmos. Oceanic Technol., 15, 1306-1319, 1998.

Ryzhkov, A. V. and Zrnic, D. S.: Assessment of rainfall measurement that uses specific differential phase, J. Appl. Meteor., 35, 2080-2090, 1996.

Sachidananda, M. and Zrnic, D. S.: Rain rate estimated from differential polarization measurements, J. Atmos. Oceanic Technol., 4, 588-598, 1987.

Short, D. A., Thiele, O. W., and McPhaden, M. J.: Optical Rain gauge performance: Second workshop on Optical Rain Gauge Measurements, NASA Technical report, Washington, USA, NASA-CP-3288, 1994.

Tokay, A., Hartmann, P., Battaglia, A., Gage, K. S., Clark, W. L., and Williams, C. R.: A field study of reflectivity and $Z-R$ relations using vertically pointing radars and disdrometers, J. Atmos. Ocean Tech., 26, 1120-1134, 2009.

Wakasugi, K., Mizutani, A., Matsuo, M., Fukao, A., and Kato, S.: A direct method for deriving drop-size distribution and vertical air velocities from VHF Doppler radar spectra, J. Atmos. Oceanic Technol., 3, 623-629, 1986. 
Wang, J.-J., Alder, R. F., Huffman, G. J., and Bolvin, D.: An updated TRMM composite climatology of tropical rainfall and its validation, J. Climate, 27, 273-284, doi:10.1175/JCLI-D-13-00331.1, 2013.

Yoneyama, K., Zhang, C., and Long, C. N.: Tracking pulses of the Madden-Julian Oscillation, B. Am. Meteorol. Soc., 94, 18711891, 2013.
Zhang, C.: Madden-Julian Oscillation: bridging weather and climate, B. Am. Meteorol. Soc., 94, 1849-1870, doi:10.1175/BAMS-D-12-00026.1, 2013. 